\title{
Establishing an evaluation tool for trauma team leader performance during trauma resuscitation
}

\author{
Faiz Tuma MD, FACS, FRCSC, Aussama Nassar MD, FACS, FRCSC, \\ Theresa Elder BS, Susan Reid MD, FRCSC
}

\begin{abstract}
Introduction: Trauma training is an important part of medical and surgical education. Evaluation of training is an essential part of medical education. A formal valid assessment method for trauma training is not available. The purpose of this study is to establish a formal and scientifically-based Trauma Team Leader Evaluation Tool.

Methods and Results: A literature review was conducted on the assessment of trauma team leaders. The available published studies were reviewed and assessed, as well as references on the principles and practice of assessment methods used in medical education. Input on points of assessment was obtained from trauma team leaders at the Hamilton General Hospital. An evaluation form was formulated with five domains, each containing five items. Definitions of the domains and items were clarified and attached to the form. The form was reviewed and revised by trauma team leaders of adult trauma and education leaders in pediatric trauma at Hamilton General Hospital and Health Science Education Program McMaster University and then finalized based on the discussed suggestions.

Conclusions: Assessment of trauma team leader performance is an important part of trauma training and feedback. Developing an assessment tool involves a comprehensive process that needs review, input, and participation from various sources related to trauma. More work to validate the tool will be needed to evaluate its utility.
\end{abstract}

Keywords: Trauma, teamwork, team leader, medical eduation, assessment methods

\section{INTRODUCTION}

Injury is a major cause of death and disability worldwide. ${ }^{1}$ In 2010, trauma death was the fifth cause of mortality in all ages in the United States and accounted for $9 \%$ of global mortality. ${ }^{2}$ For every death, it is estimated that there are dozens of hospitalizations and hundreds of emergency department visits. Therefore, there is an increasing demand to improve trauma care and service. Trauma care is a major part

Corresponding author: Theresa Elder

Contact Information: Elder1ta@cmich.edu

DOI: 10.12746/swrccc.v7i28.543 of the health care provided worldwide and has developed significantly in the past few decades. Organized approaches to trauma prevention and treatment are needed to improve care, with one major aspect being better training of trauma personnel.

Trauma training programs and fellowships have steadily increased over time, and trauma training has become a growing part of surgical education and training. Trainees of all levels and with varying degrees of surgical background participate in trauma rotations. Measuring progress and evaluating training is an essential part of medical education, with several methods of evaluation being used. ${ }^{3,4}$ Some of these methods or tools are well designed and studied, while others, such as subjective non-systematic observation, are poorly-structured. 
There are no published formal evaluation tools to assess the performance of a Trauma Team Leader (TTL), in general or specifically during trauma resuscitation. Since resuscitation is the core activity of the trauma team and leader, evaluating this performance would assist in assessing training progress and efficiency level in trauma care. A direct observation assessment is a suitable method for this type of evaluation. It assesses the domains that are involved in TTL work (clinical skills, communication, teamwork, presentation skills, organization and work habits). ${ }^{5}$

This study was conducted to develop a tool to evaluate TTL performance during trauma resuscitation. This tool can then be used to assess the training progress of trauma trainees of various levels and has potential future application in assessing practicing TTL. We introduce our novel tool and discuss the methods involved in its development and its basic principles and concepts.

\section{Methods AND RESULTS}

A PubMed search was conducted to review the available published studies related to TTL evaluation. The search was conducted using the key words "trauma", "injury", "care", "service", "team leader", "trauma resuscitation", "evaluation", and "assessment". The result of the search revealed three studies related to the main theme of TTL evaluation.

The first was a prospective study conducted by Sugrue et al which assigned a score to each team leader to assess his or her performance. The score was calculated by a panel of trauma management specialists, who assessed different categories of care performed during initial trauma resuscitation. ${ }^{6}$ The other two studies utilized video recordings of trauma teams to evaluate their performance retrospectively. ${ }^{7,8}$ While these studies helped analyze the quality of the trauma team's performance, they did not provide a comprehensive tool that could assess overall TTL performance nor the level of training progress of trainees.

The project of establishing a TTL evaluation tool was discussed with the trauma staff and faculty of Hamilton
Health Sciences - General Site for input on both the process and aspects of evaluation. After a review of references on the principles and practice of assessment methods used in medical education, a draft of the general evaluation form was developed..$^{9-11}$ Initial drafting was made by the trauma director, trauma surgeons, trauma fellows, trauma nurses, and ATLS instructors. This form consists of five domains: Critical Assessment, Communication and Leadership, Decision Making, Clinical Performance, and Teaching. Each domain contains 5 items that assist with scoring purposes, ranging from N/A-Non Assessable, 1-Poor, 2-Marginal, 3-Good, 4-Very Good, and 5-Outstanding. A description of each domain and details of its scoring criteria are attached to the evaluation form. The draft was reviewed with the trauma staff at Hamilton General Hospital and McMaster University Hospital, the faculty of McMaster University, trauma fellows, residents and nurses. The form was modified to implement the contributors' suggestions for improvement to establish a final evaluation form, which is attached in Tables I and II.

\section{Conclusion}

There are no published evaluation tools to comprehensively assess trauma team leader performance to date. Based upon literature review, medical education performance assessment guidelines, and trauma faculty and personnel expert input, a comprehensive evaluation tool was formulated. This tool assesses the necessary skills of effective trauma team leaders, many of which lie outside of the domain of technical skills but have a vital role in trauma outcomes. The skills being measured are not only applicable to trauma surgery physicians, but also to physicians of any specialty that involves running trauma codes, particularly emergency medicine. Furthermore, the form is designed in such a way that any person with trauma experience is eligible to evaluate another. This assessment aims to provide valuable performance feedback and a means to measure progress, which enhances the learning experience of trainees in any type of trauma setting. Formal validation and assessment of the tool's reliability will be the next step in utilizing the tool in medical education and clinical practice. 
Table I. Trauma Team Leader (TTL) Evaluation form

Staff/Evaluator:

Level of trainee/experience level.

.......................




Table II. Descriptions of evaluation form criteria and grading

\begin{tabular}{|c|c|}
\hline \multicolumn{2}{|c|}{ GRADING SCALE } \\
\hline (1) poor & Consistently performing below standards of patient care. Serious improvement is required \\
\hline (2) marginal & Occasionally missing important aspects of patient care; needs review/improvement \\
\hline (3) good & Satisfactory performance in most patient care situations \\
\hline (4) very good & Consistently performing safely and maintaining standards of patient care \\
\hline (5) outstanding & Always performing and maintaining the highest standards of patients care \\
\hline (0) not assessable & Unable to assess performance \\
\hline \multicolumn{2}{|c|}{ A. CRITICAL ASSESSMENT } \\
\hline 1 & Promptly arriving to the trauma resuscitation area to prepare for trauma management \\
\hline 2 & Gathering information related to the trauma efficiently from different sources \\
\hline 3 & $\begin{array}{l}\text { Analyzing available data from history, clinical assessment and investigations to guide trauma } \\
\text { management }\end{array}$ \\
\hline 4 & $\begin{array}{l}\text { Prioritizing the steps of management according to the assessment info and the patient's response to } \\
\text { the initial resuscitation }\end{array}$ \\
\hline 5 & Reassessing the patient status and modifying management as needed \\
\hline \multicolumn{2}{|c|}{ B. COMMUNICATION AND LEADERSHIP } \\
\hline 1 & $\begin{array}{l}\text { Introducing self and other members to each other and maintaining proper communication during } \\
\text { resuscitation }\end{array}$ \\
\hline 2 & Delegating level-appropriate tasks to involved team members \\
\hline 3 & $\begin{array}{l}\text { Maintaining clarity of instruction in terms of speech volume and appropriate level of detail, } \\
\text { specifying the person to receive the instructions, and ensuring closed loop communication. }\end{array}$ \\
\hline 4 & $\begin{array}{l}\text { Maintaining an environment that limits attending personnel to only those directly involved; limiting } \\
\text { outside noise, and sequentially organizing various aspects of care }\end{array}$ \\
\hline 5 & Maintaining a calm demeanor during high-stress situations \\
\hline \multicolumn{2}{|c|}{ DECISION MAKING } \\
\hline 1 & Interpreting the data and using this to determine the plan of management \\
\hline 2 & $\begin{array}{l}\text { Using the available resources (labs, imaging, procedural equipment) and specialty services } \\
\text { (general, orthopedic and/ or thoracic surgery, neurosurgery and anesthesia }\end{array}$ \\
\hline 3 & $\begin{array}{l}\text { Tailoring the pace of performance according to the trauma severity and situation, and preparing for } \\
\text { the subsequent steps in advance. }\end{array}$ \\
\hline 4 & Supporting other members when time is critical \\
\hline 5 & $\begin{array}{l}\text { Awareness of any limitations in management, such as unavailability of a specialty service, some } \\
\text { devices, blood products or medications }\end{array}$ \\
\hline
\end{tabular}


Table II. Descriptions of evaluation form criteria and grading (Continued)

\begin{tabular}{|l|l|}
\hline \multicolumn{2}{|l|}{ CLINICAL PERFORMANCE } \\
\hline 1 & Applying ATLS or other relevant protocols properly \\
\hline 2 & Responding to all clinical findings as appropriate \\
\hline 3 & $\begin{array}{l}\text { Utilizing a broad and up-to-date knowledgebase of trauma practice and using evidence-based } \\
\text { practice }\end{array}$ \\
\hline 4 & Practicing quality skills while performing a variety of bedside procedures \\
\hline 5 & $\begin{array}{l}\text { Proactively anticipating the direction headed following initial resuscitation, preparing for potential } \\
\text { additional interventions and resources that may be required }\end{array}$ \\
\hline MEDICAL TEACHING \\
\hline 1 & $\begin{array}{l}\text { Demonstrating awareness of the learners involved, and setting appropriate learning objectives for } \\
\text { the given situation }\end{array}$ \\
\hline 2 & $\begin{array}{l}\text { Appropriately delegating roles and assignments according to the learner's level of experience and } \\
\text { permissiveness of the situation }\end{array}$ \\
\hline 3 & Sharing educational clinical findings with learners during appropriate teaching moments \\
\hline 4 & Discussing the case with learners, and providing opportunities to answer questions \\
\hline 5 & Giving feedback to the learners \\
\hline
\end{tabular}

Article citation: Tuma F, Nassar A, Elder T, Reid S. Establishing an evaluation tool for trauma team leader performance during trauma resuscitation. The Southwest Respiratory and Critical Care Chronicles 2019;7(28):38-43

From: Central Michigan University College of Medicine, Department of Surgery, Saginaw, MI (FT, TE); Stanford University, Department of Surgery, Stanford, CA (AN); McMaster University, Department of Surgery, Hamilton, Ontario, Canada (SR)

Submitted: $1 / 26 / 2019$

Accepted: $4 / 3 / 2019$

Reviewers: Sanket Thakore MD, Anuj Shah MD Conflicts of interest: none

This work is licensed under a Creative Commons Attribution-ShareAlike 4.0 International License.

\section{REFERENCES}

1. Injuries. World Health Organization. Accessed January 2018. Available at: http://www.who.int/topics/injuries/about/en/.

2. National Vital Statistics System, National Center for Health Statistics, CDC. Office of Statistics and Programming, National Center for Injury Prevention and Control, CDC using WISQARSTM. Accessed December 2018. Available at: https://www.cdc.gov/injury/wisqars/index.html.

3. Roff S, McAleer S, Harden R, et al. Development and validation of Dundee ready education environment measure (DREEM). Med Teach 1997;19:295-299.

4. Roff S. The Dundee ready educational environment measure (DREEM)-a generic instrument for measuring students' perceptions of undergraduate health professions curricula. Med Teach 2005;27(4):322-325.

5. Epstein RM. Assessment in medical education. The New Engl J Med 2007;356:387-96. 
6. Surgue M, Seger M, Kerridge R, et al. A prospective study of the performance of the trauma team leader. The J TraumaJan 1995;38:79-82.

7. Richie PD, Cameron PA. An evaluation of trauma team performance by video recording. Aust N Z Surg 1999;69(31): $183-186$.

8. Lubbert PH, Kaasschieter EG, Hoorntje LE, et al. Video registration of trauma team performance in the emergency department: the results of a 2-year analysis in a level 1 trauma center. J Trauma 2010;67(6):1412-20.
9. Streiner D, Norman G. Health measurement scales: A practical guide to their development and use. 2nd ed. Oxford: Oxford University Press; 1995.

10. Flin R, et al. The Non-Technical Skills for Surgeons (NOTSS) System Handbook V1.2. Accessed January 2018. Available at https://research.abdn.ac.uk/applied-psych-hf/surgery/

11. Van Der Vleuten CPM. The Assessment of professional competence: developments, research and practical implications. Adv Health Sci Educ 1996;1(1):41-67. 